\title{
Periurethral abscess drained by iatrogenic urethral fistula in a middle-aged man
}

\author{
Gaurav Garg, ${ }_{1}^{1}$ Apul Goel, ${ }^{1}$ Deepanshu Sharma, ${ }^{2}$ Siddharth Pandey ${ }^{2}$
}

'Department of Urology, King George's Medical University, Lucknow, Uttar Pradesh, India ${ }^{2}$ Department of Urology, King George's Medical University, Lucknow, Uttar Pradesh, India

\section{Correspondence to Dr Gaurav Garg, gougarg@gmail.com}

Accepted 11 April 2018

\section{DESCRIPTION}

A 35-year-old man was referred to our urology department in June 2016 from a local hospital. The patient initially presented with high-grade fever, painful scrotal swelling and acute urinary retention (AUR) 3 months back to a local practitioner and was diagnosed as a case of periurethral abscess. He was advised oral antibiotics, and a small calibre (8 Fr) catheter was placed per-urethrally in the bladder. After few days, the catheter got removed accidentally, and the patient again went into AUR. The discharge card given to the patient mentioned that the patient had multiple failed attempts of per-urethral catheterisation, and in order to relieve the patient's symptoms, the treating practitioner just attempted a blind incision over the swelling. Pus mixed with urine came out. This turned out to be a blessing in disguise as it drained urine and led to resolution of the abscess. Subsequently, a urethral catheter was advanced into the opening in the scrotum, and the patient was referred. The patient had a history of multiple urethral dilatations in the last 3 years (last done in March 2016). He denied any history of local trauma, sexually transmitted diseases, diabetes, alcohol abuse or

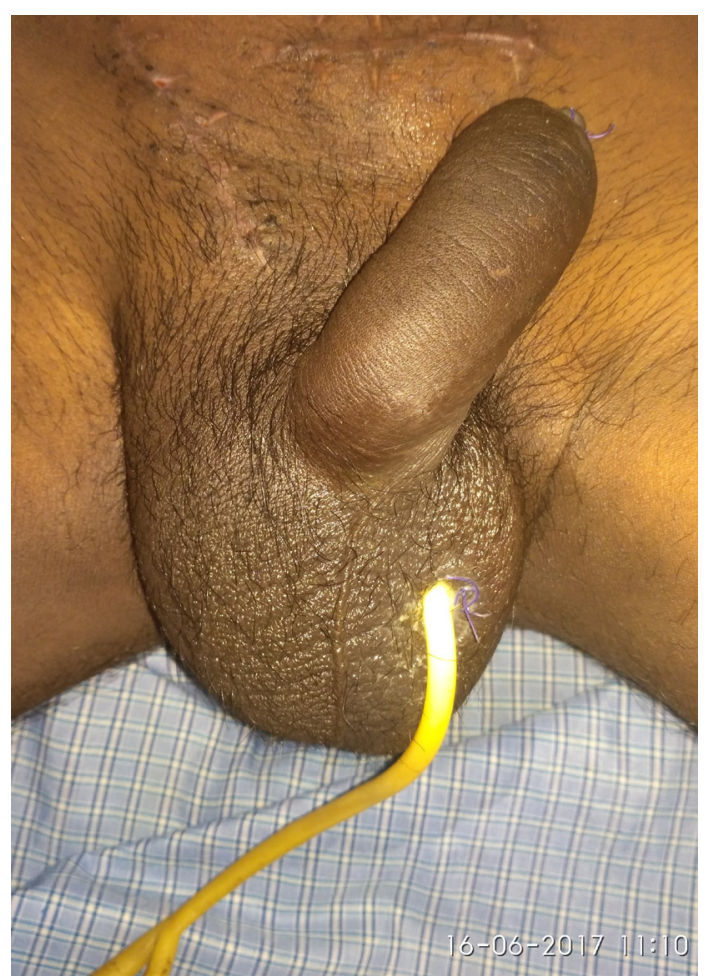

Figure 1 Clinical image showing Foley catheter inserted through the scrotum.

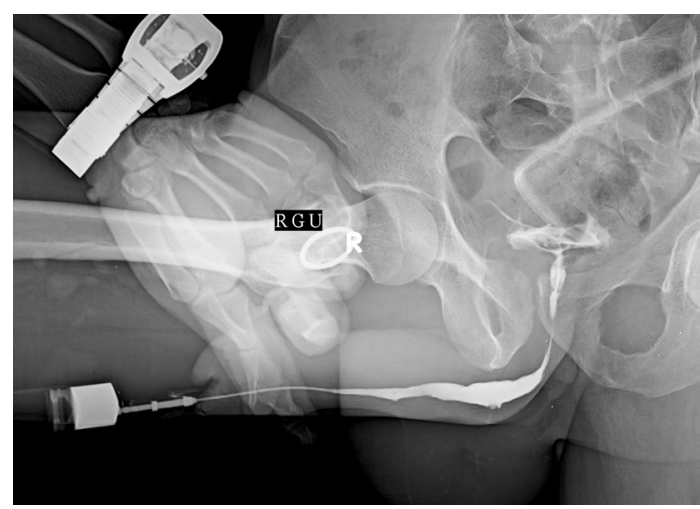

Figure 2 Retrograde urethrogram image showing stricture involving almost complete anterior stricture.

steroid intake. On investigations, his routine blood/ urine tests including sugar levels were normal, and screening tests for HIV were negative. His local examination revealed lichen sclerosus over the glans penis and a 14-Fr Foley catheter was placed through the scrotum (figure 1). The catheter was draining clear urine and contrast instillation through the catheter confirmed placement of the catheter in bulbar urethra. The urethral catheter was removed, and a suprapubic catheter was placed. After 4 weeks, the scrotal wound healed. Retrograde urethrogram revealed a pan-urethral stricture (figure 2), which was managed by Johannson's staged urethroplasty. The following urethroplasty after catheter removal, the patient is having a good flow (Qmax $>15 \mathrm{~mL} / \mathrm{s}$ ) with minimal postvoid residual urine in the bladder $(<25 \mathrm{~mL})$. The standard management of periurethral abscesses must include surgical exploration with culture-specific/ broad-spectrum antibiotics. ${ }^{1} 2$ To ensure adequate urine drainage a per-urethral catheter may be placed

Learning points

- The standard management of periurethral abscesses must include surgical exploration of the abscess with culture-specific/broadspectrum antibiotics.

- To ensure adequate urine drainage, a per-urethral catheter may be placed if the urethra is intact, else urinary diversion by means of suprapubic catheter must be performed.

- In rare scenarios in case of periurethral abscess, iatrogenic placement of a urethral catheter through scrotum may lead to drainage of abscess and improvement in clinical condition. 
if the urethra is intact, else urinary diversion by means of suprapubic catheter must be performed. ${ }^{12}$ Iatrogenic placement of a catheter through scrotum has been described previously only once in which the authors have described a case of 46-year-old man who presented with a scrotal abscess and developed an iatrogenic urethroscrotal fistula due to wrong catheterisation. ${ }^{3}$ The authors proposed that iatrogenic catheter placement with subsequent urethroscrotal fistula formation stopped the progress of scrotal abscess into Fournier's gangrene. ${ }^{3}$

Contributors GG and AG: concept, design, supervision, processing, writing manuscript and critical analysis. DS: concept, supervision, writing manuscript and critical analysis. SP: supervision, processing, writing manuscript and critical analysis.

Funding The authors have not declared a specific grant for this research from any funding agency in the public, commercial or not-for-profit sectors.
Competing interests None declared.

\section{Patient consent Obtained.}

Provenance and peer review Not commissioned; externally peer reviewed.

(c) BMJ Publishing Group Ltd (unless otherwise stated in the text of the article) 2018. All rights reserved. No commercial use is permitted unless otherwise expressly granted.

\section{REFERENCES}

1 Kenfak-Foguena A, Zarkik Y, Wisard M, et al. Periurethral abscess complicating gonococcal urethritis: case report and literature review. Infection 2010;38:497-500.

2 Bozkurt A, Karabakan M, Soyturk M, et al. Urethrogluteal fistula developing secondary to the use of clean intermittent self-catheterization: first case report in the literature. Case Rep Urol 2014;2014:1-4.

3 Stizzo M, Arcaniolo D, Quattrone C, et al. Scrotal Abscess Drained by latrogenic Urethral Fistula in an Adult Diabetic Male. Case Rep Urol 2017;2017:1-3.

Copyright 2018 BMJ Publishing Group. All rights reserved. For permission to reuse any of this content visit

http://group.bmj.com/group/rights-licensing/permissions.

BMJ Case Report Fellows may re-use this article for personal use and teaching without any further permission.

Become a Fellow of BMJ Case Reports today and you can:

- Submit as many cases as you like

- Enjoy fast sympathetic peer review and rapid publication of accepted articles

- Access all the published articles

Re-use any of the published material for personal use and teaching without further permission

For information on Institutional Fellowships contact consortiasales@bmjgroup.com

Visit casereports.bmj.com for more articles like this and to become a Fellow 